\title{
Oral Topotecan Hydrochloride
}

National Cancer Institute

\section{Source}

National Cancer Institute. Oral Topotecan Hydrochloride. NCI Thesaurus. Code C63477.

An oral formulation of the hydrochloride salt of topotecan, a semisynthetic derivative of the quinoline alkaloid camptothecin, with potential antineoplastic activity. Topotecan selectively inhibits topoisomerase I activity by stabilizing topoisomerase I-DNA covalent complexes during the $\mathrm{S}$ phase of the cell cycle, thereby inhibiting religation of topoisomerase I-mediated single-strand DNA breaks and producing potentially lethal double-strand DNA breaks when encountered by the DNA replication machinery. 